\title{
Editorial: SAICSIT 2016 special section
}

Philip Machanick sacj.editor@gmail.com

Department of Computer Science, Rhodes University, South Africa

\section{Introduction}

South African Computer Journal in this issue incorporates a special section containing extended papers from the SAICSIT 2016 conference. In this instance, the papers were ready in time for the regular issue so rather than hold them back, we included them in the regular July 2017 issue.

We also have in progress a special issue on ICT for education, with many papers still under review. That issue has been slowed down by issues out of our control, but we hope to have in out before the end of the year.

Since we were included in the Scopus index last year, $S A C J$ has seen a small increase in international authors submitting papers. It is still too early to assess whether this will enhance our publication rate, as an increase in submissions does not necessarily imply an increase in publishable material. Nonetheless we welcome our raised profile and hope that we will start to see good submissions from elsewhere particularly those that enhance our standing as a regional journal.

What follows is a summary of this issue in two parts: the regular contributions and an introduction to the guest editorial by the SAICSIT special section editors. The guest editorial appears separately at the head of the papers in the special section.

\section{Regular papers}

We have four regular papers in this issue.

Clinning and Marnewick's investigation into "Incorporating sustainability into IT project management" uses a project management sustainability maturity model to show that there is much still to be done in this field.

In "Adaptive SVM for Data Stream Classification", Lawal and Abdulkarim evaluate Support Vector Machine (SVM) learning using human action classification from videos and spam flitering.

In "An Assessment of Algorithms for Deriving Failure Deterministic Finite Automata" Nxumalo et al. assess the effectiveness of four algorithms for generating failure deterministic finite automata (FDFAs).

Machanick, P. (2017). Editorial: SAICSIT 2016 special section [Editorial]. South African Computer Journal 29(1), viiviii. https://doi.org/10.18489/sacj.v29i1.513

Copyright (C) the author(s); published under a Creative Commons NonCommercial 4.0 License (CC BY-NC 4.0). $S A C J$ is a publication of the South African Institute of Computer Scientists and Information Technologists. ISSN 1015-7999 (print) ISSN 2313-7835 (online). 
Finally, in "Optimizing Capacity Assignment in Multiservice MPLS Networks", Rassaki and Nel assess their new algorithm that computes shortest routes, assigns optimal flows to newly found routes, while at the same time determining optimal link capacities.

\section{Special section and reviewing}

The special section is edited by Duncan Coulter and Carl Marnewick of University of Johannesburg.

The five papers in this issue represent many hours of diligent work on their part chasing down reviewers and helping the authors to meet the standards of $S A C J$. For this I thank them. A few papers did not make it to this issue's deadline; we may still have a few more extended SAICSIT 2016 papers in a later edition.

One of the hardest tasks of the journal editor is finding willing and able reviewers who will deliver reviews on time. If you are keen to get your work published, start by volunteering to review. You can either email me or simply add reviewer to your profile as a user on our site. If you do that please also be sure to add in some keywords into your reviewing interests so we can find you.

\section{Changes and thanks}

Since last issue, Kirstin Krauss has stepped down as an editor; we have replaced him in the Information Systems section by Hugo Lotriet from UNISA. Thank you both: your service is much appreciated. Also joining us is an additional Computer Science editor, Sigrid Ewert from University of the Witwatersrand. Our editors do much of the hard work in moving papers through the pipeline - finding reviewers, chasing up after tardy reviewers and making sense of differences of opinion between reviewers. That is not to say I am complaining about the quality of reviews: there are often very legitimate differences and the experience and professionalism of our editors is what makes it possible to arrive at good decisions.

It is not only when editors arrive and leave; I appreciate them all the time. And I would also like to add thanks to everyone who makes this journal what it is: editors, authors, reviewers and our web site host: University of Cape Town Department of Computer Science. Without all of you and our parent society, South African Institute of Computer Scientists and Information Technologists (SAICSIT), we would not have a quality regional journal that can showcase computer science and information systems research from our part of the world.

One final thank you: if the South African government did not have a system for accrediting journals, imperfect though it may be, it would be much more difficult to maintain a small quality journal against so much competition by the growing cottage industry of low-quality open access journals. Accreditation of this form is a model other developing countries should consider. 